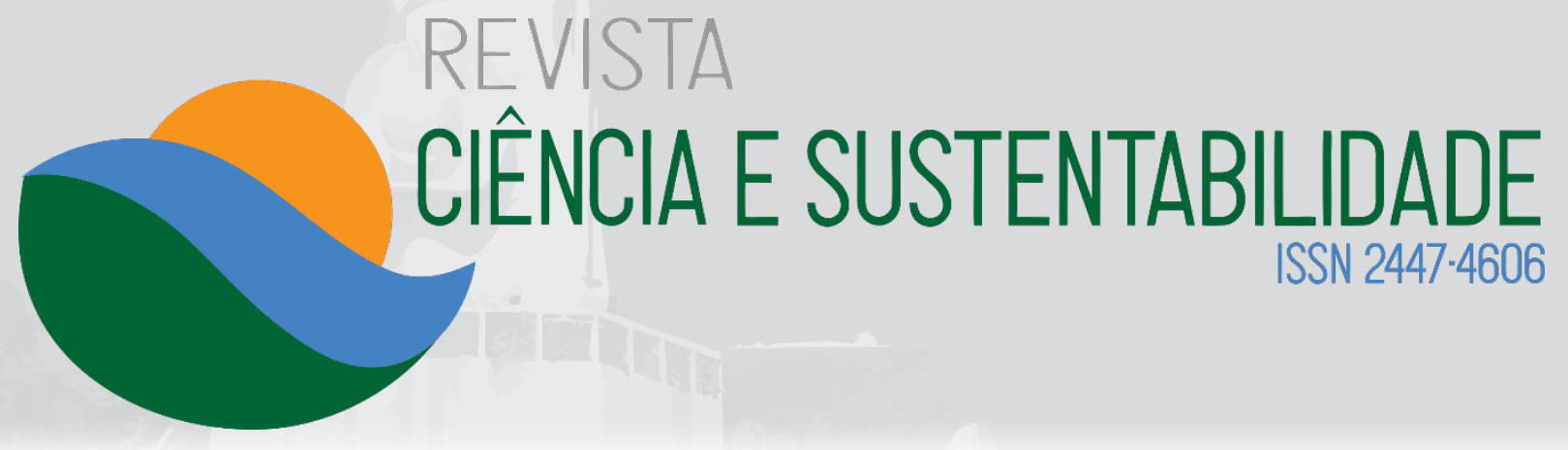

\title{
Modo de vida comunitário e preservação ambiental: Um estudo sobre a participação social na Prainha do Canto Verde
}

\author{
Communal way of life and environmental preservation: a study of social \\ participation in Prainha do Canto Verde
}

\begin{abstract}
Daniel Welton Arruda Cabral Universidade Federal do Ceará (UFC) Graduado em Psicologia pela Universidade de Fortaleza. Mestre em Psicologia pela Universidade federal do Ceará. Doutorando em psicologia pela Universidade Federal do Ceará. daniel_welton@hotmail.com

\section{Zulmira Aúrea Cruz Bomfim Universidade Federal do Ceará (UFC) Graduada em Psicologia pela Universidade Federal do Ceará. Mestrado em Psicologia pela Universidade de Brasília. Doutorado em psicologia pela Pontifícia Universidade Católica de São Paulo. Atualmente é Professora Associado IV da Universidade Federal do Ceará no Departamento de pós- graduação em psicologia. zulaurea@gmail.com}

\section{Renata Cristina Façanha de Meneses Universidade Federal do Ceará (UFC) Graduada em Psicologia pela Universidade Estadual do Ceará. Residência em Assistência em Transplante pela Universidade Federal do Ceará. Especialista em Neuropsicologia}

\begin{abstract}
Resumo
Esta pesquisa investigou as percepções e sentimentos de moradores com forte engajamento comunitário, encontrando uma correlação entre a participação social e afetos de agradabilidade e pertencimento comunitário, geradores de coesão social e preservação ambiental. A fundamentação teórica utilizada foi a Psicologia Ambiental de viés transacional, que estuda o ambiente a partir de suas dimensões físicas, econômicas, sociais e culturais, assim como do arcabouço teórico de uma Psicologia Social que entende a afetividade como uma dimensão mediadora da ação transformação. A pesquisa teve como objetivo geral analisar a inter-relação entre os processos de participação social da comunidade da Prainha do Canto Verde e a relação afetiva pessoaambiente. Os objetivos específicos foram: investigar o modo de vida dos moradores da comunidade e entender de que maneira ocorre a participação comunitária dos moradores da localidade. A metodologia de geração de dados realizada através da formação de grupos focais com quinze moradores da localidade, adultos, de ambos os sexos, de diferentes níveis escolares e engajados em atividades comunitárias. A escolha da comunidade se deu por conta de um forte histórico de participação social realizado há décadas e que contribuiu para diversas conquistas e melhorias socioambientais. A participação comunitária se evidenciou neste estudo como parte da identidade destes sujeitos, formada desde a infância,
\end{abstract}


pela Unichristus. Mestranda em Psicologia pelo Programa de Pós-Graduação em Psicologia na Universidade Federal do Ceará.

renatafacanha@gmail.com especialmente pela identificação com a participação dos pais. A participação se mostrou vivenciada a partir de sentimentos como "desejo" e "paixão"; e motivada pela vontade de preservar o local e o modo de vida para seus filhos. Mostrou-se ainda relacionada ao pertencimento e promotora de orgulho, fazendo com que sentimentos de solidariedade e de partilha coexistam para além das disputas internas. O rodízio no protagonismo dos moradores bem como o apreço à participação social como um valor passado de forma transgeracional no seio familiar mostraram-se fundamentais para a perpetuação do engajamento da comunidade e para a promoção de laços comunitários.

Palavras-chave: Participação. Comunidade. Psicologia comunitária. Modo de vida. Unidade de conservação.

\section{Abstract}

This research investigated the perceptions and feelings of residents with strong community engagement, finding a correlation between social participation and affections of community enjoyment and belonging, generating social cohesion and environmental preservation. The theoretical basis used was the Environmental Psychology of Transactional Bias, which studies the environment from its physical, economic, social and cultural dimensions, as well as from the theoretical framework of a Social Psychology that understands affectivity as a mediating dimension of the transformation action. The research aimed to analyze the interrelationship between the processes of social participation of Prainha do Canto Verde community and affective relationship person-environment. The specific objectives were: to investigate the way of life of community residents and understand how is the community participation of local residents. The data generation methodology was performed through the formation of focus groups with fifteen local residents, adults of both sexes, of different school levels and engaged in community activities. The choice of community was due to a strong history of social participation carried out for decades and that contributed to several achievements and socioenvironmental improvements. Community participation was evidenced in this study as part of the identity of these subjects, formed from childhood, especially by identification with parental involvement. Participation was shown through feelings like "desire" and "passion"; and motivated by the desire to preserve the place and way of life for 
their children. It has also been shown to be related to the belonging and promoter of pride, making feelings of solidarity and sharing coexist in addition to internal disputes. Rooting in the protagonism of the residents, as well as the appreciation of social participation as a transgenerational value in the family have been fundamental for the perpetuation of community engagement and the promotion of community ties.

Keywords: Participation. Community. Community psychology. Way of life. Conservation unit. 


\section{INTRODUÇÃO}

Esta pesquisa investigou a inter-relação entre os processo de participação social da Prainha do Canto Verde (PCV) e a relação afetiva de seus moradores com a comunidade. A partir de uma comunidade tradicionalmente engajada e com forte participação social de seus moradores, o trabalho se propôs a identificar quais são os fatores que propiciam este engajamento bem como quais as repercussões da participação. Para isso a pesquisa investigou quais as percepções, pensamentos, sentimentos dos moradores em relação a duas categorias temáticas: modo de vida comunitário e participação social.

Antes de começarmos a pensar sobre a participação social dos moradores, é imprescindível delimitar sobre que tipo de participação estamos falando. Os seres humanos desenvolvem a sua consciência a partir do contato de uns com os outros. A "autorregulação" humana é o resultado das mediações realizadas pelas interações sociais demarcadas pela cultura e internalizadas pelo sujeito (VYGOTSKY, 1998).

É através do contato interativo com o outro que nos formamos: "Como nenhum homem é uma ilha e desde suas origens o homem vive agrupado com seus iguais, a participação sempre tem acompanhado as formas históricas que a vida social foi tomando" (BODERNAVE, p. 12, 1983). Assim podemos falar que a formação da consciência do indivíduo está relacionada a sua participação social desde a infância.

Freire (1979) coloca a participação como fundamental para a conscientização dos sujeitos sociais. Para ele, é através da participação, do engajamento com o outro e do diálogo que o sujeito atinge a autonomia e o pensamento crítico. Apesar de Bodernave e Freire se utilizarem do mesmo termo nas citações acima, a saber, "participação", ambos estavam descrevendo processos diferentes. Sawaia (2002) alerta que participamos da vida social em diferentes esferas: intimidade, trabalho, política, família, comunidade. Essas formas de participação variam de intensidade, desde a simples adesão do indivíduo até a sua total absorção.

Nosso estudo investigou a participação dos sujeitos na esfera pública, ou seja, a participação implicada na busca da modificação das estruturas sociais. Tivemos como foco a participação de base comunitária e viés político, socialmente engajada, que busca uma transformação social local, embora que, para tanto, por muitas vezes tenha que se articular com esferas globais. 


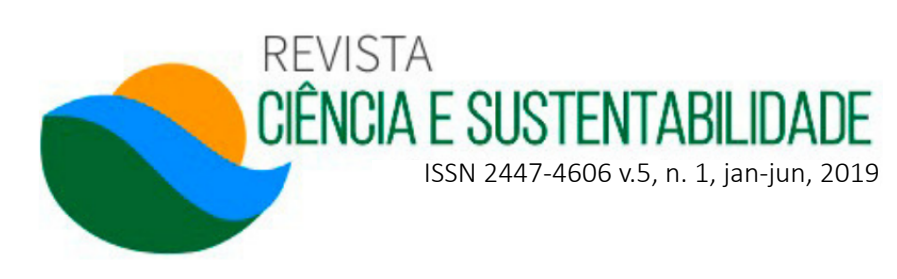

Para Scherer-Warren (2002), algumas das formas de participação dos sujeitos nas esferas públicas é por meio do associativismo civil e dos movimentos sociais, elas possibilitam a formação de identidades coletivas e ideários comuns, que são os pré-requisitos para a demanda coletiva de direitos e para a criação de novos valores e normas para a vida societária. $O$ autor exemplifica tais formas de participação por meio do associativismo civil: grupos de ajuda mútua, associações de classe, organizações não-governamentais, organizações de defesa da cidadania, associativismo de base religiosa e, por fim, associações comunitárias, foco da investigação deste trabalho.

Demo (2009) defende que existe uma tendência histórica à dominação, ou seja, a existência de um lado minoritário que comanda e um majoritário que é comandado. A participação não ocorre de maneira preexistente ou natural, mas como conquista mediante processo infindável e em constante vir-a-ser, que sempre se refaz. Isso implica afirmar que a participação, sob esta perspectiva, pode ser concebida como resultado de um processo ativo de conquistas que estão em constante vir-a-ser. Mesmo quando aparenta ser concedida ou imposta, cabe ao sujeito aceitá-la ou não, tendo em vista que sempre é implícita uma ação na luta por poder.

No âmbito comunitário, esta luta é muitas vezes difícil de ser iniciada. Para Galdino (2014), nos momentos iniciais, os parceiros externos são fundamentais para a superação de situações de precariedade e de exploração as quais muitas comunidades estão sujeitas. Estes parceiros comumente são profissionais vinculados à rede de políticas públicas, que trabalham diretamente com a comunidade como agentes de saúde: psicólogos, assistentes sociais, etc. Nestes casos é fundamental a realização de um planejamento participativo para a efetivação de uma transformação social destes espaços. É imperativo que o técnico não se coloque como condutor das políticas, mas sim como um agente facilitador, mobilizador dos recursos comunitários. É preciso entender que os efetivos conhecedores da realidade são os moradores comunitários, tomando cuidado para não privilegiar aspectos técnicos em detrimento do saber popular e local, e mantendo abertura à compreensão das questões comunitárias locais, pois só assim será possível uma atuação efetiva e mobilizadora.

Bodernave (1983) relata que a participação tem duas bases complementares, uma afetiva e outra instrumental. Dentro da perspectiva dos afetos, participamos de um grupo porque este nos gera prazer e bem-estar. Já sob o viés instrumental, participamos porque é mais eficaz se conquistar uma meta de forma coletiva do que 
individualmente.

Para Sawaia (2002), até os anos 1980 o paradigma da análise e planejamento da participação era caracterizado pela ênfase na coletividade, na objetividade e na racionalidade. Assim, participação pressupunha um alto nível de conscientização política e social, mobilização coletiva e seu alvo de ação era a estrutura social, seja transformadora ou reformista. A intimidade normalmente era pouco considerada e as ações eram focadas em um alvo no futuro.

Posteriormente, a participação passou a considerar no escopo das questões coletivas, aspectos concernentes à individualidade e afetividade humanas. Essas mudanças superam a dicotomia entre razão e emoção, bem como o reducionismo que entendia o termo "participação" como algo exterior ao sujeito. Para Sawaia (2002, p.118) "Autonomia, emancipação, e diversidade tornam-se valores éticos mais aplaudidos em substituição à liberdade e à igualdade". Se, por um lado, a inclusão de questões relativas às subjetividades individuais dentro dos movimentos coletivos aumenta a compreensão sobre a participação comunitária, por outro, também há o risco de cairmos em um reducionismo subjetivista, que nega as outras dimensões da participação (SAWAIA, 2002). O grande desafio é incluir nos estudos de participação a esfera afetiva, dando voz a questões de cunho subjetivo e particular sem se desfocar da luta pela modificação das questões estruturais de nossa sociedade, em uma busca pela diminuição das desigualdades sociais, das injustiças, e da emancipação humana.

Scherer-Warren (2002) traz a importância de novas redes que vêm se formando a partir do mundo virtual. O aumento do alcance das informações através da virtualidade das redes aponta para uma integração de diferentes lutas por direitos. As associações comunitárias, por exemplo, passam a entrar em contato com outros movimentos sociais de luta por direitos mais amplos, articulando a memória com a utopia da transformação. Isto resulta em uma ação local que tem como plano de fundo um pensamento global.

\section{METODOLOGIA}

Este estudo é parte de uma pesquisa vinculada ao Programa de Pós-Graduação em Psicologia da Universidade Federal do Ceará. Ela foi realizada a partir de um viés 
etnográfico e investigou a relação entre participação, modo de vida comunitário e relação afetiva sujeito-ambiente.

Nossa investigação abordou as percepções, pensamentos e sentimentos sobre a participação social e o modo de vida comunitário na Prainha do Canto Verde (PCV). Para tanto, foi utilizado o discurso dos moradores a partir da realização de grupos focais compostos por dez a quinze membros, juntamente às observações provenientes dos diários de campo com os registros etnográficos realizados pelo pesquisador. $O$ público-alvo participante dos grupos focais foram moradores da localidade de ambos os sexos, na faixa etária de dezoito a setenta e três anos, com diferentes níveis de escolaridade (de analfabeto até nível superior completo) e membros engajados da Associação de Moradores da Prainha do Canto Verde (AMPCV).

Antes da realização da pesquisa, por se tratar de localidade situada em uma Reserva Extrativista foi necessário o envio dos objetivos e metodologia do estudo ao Instituto Chico Mendes, para emissão de uma autorização. A autorização, bem como o Termo de consentimento livre, foi lido, debatido coletivamente e assinado pelos moradores antes do primeiro grupo focal.

A abordagem teórica utilizada foi a da Psicologia Ambiental de viés transacional, que estuda o ambiente não só a partir de suas dimensões físicas, como também econômicas, sociais, culturais, e históricas. Também foi utilizado no arcabouço teórico a Psicologia Social, comprometida com as dimensões sensíveis das emoções e dos sentimentos e que entende a afetividade como uma dimensão mediadora da ação transformação.

Os grupos focais buscaram investigar duas categorias temáticas. A primeira investigou como se davam os processos de participação popular, o que lhes motivava/ desmotivava e como se organizavam. As perguntas utilizadas para iniciar esta discussão nos grupos focais foram: Como se dá a participação popular na PCV? O que leva os sujeitos a participar/não participar das atividades? A segunda categoria investigada foi o modo de vida na localidade, especialmente a relação dos sujeitos com o ambiente (incluindo aí a própria comunidade). Isso foi realizado a partir dos seguintes questionamentos: Como é a vida na PCV? Como a comunidade se relaciona? O que pensam em relação a Reserva Extrativista (Resex)? A pergunta sobre a Reserva Extrativista foi incluída porque se trata de uma conquista fundamental para a preservação ambiental da localidade, bem como possui forte relevância para a 
manutenção do modo de vida comunitário.

\section{CARACTERIZAÇÃO E HISTÓRICO DA PRAINHA DO CANTO VERDE}

A Prainha do Canto Verde está localizada no município de Beberibe, Estado do Ceará. Sua gênese remete à segunda metade do século XIX, quando Joaquim Caboclo, junto com sua esposa Filismina, construíram a primeira casa de taipa. Outras famílias também começaram a chegar ao entorno da praia, como a de Raimundo Cabloco, que tinha um filho por nome Raimundo Canto Verde, que morava na vizinhança e cotidianamente lá ia pescar. Achando ele a praia muito bonita pelas imensas quantidades de verde, começou a chamá-la de Prainha, a qual logo passou a ser conhecida como Prainha do Canto Verde (PRAINHA, 2011).

Entre numerosos filhos, a PCV ganha sua primeira liderança com Bernardinho, filho de Zé Cariri. Bernadinho era autodidata: aprendeu a ler enquanto pescava na solidão do mar, sendo um dos poucos alfabetizados da redondeza. A primeira notícia documentada da PCV é do ano de 1928, quando Bernardino navegou em uma simples jangada até Belém do Pará em uma viagem de 14 dias que tinha como fim enaltecer a figura do pescador. Em 1941, "Jacaré", outra liderança local, em conjunto com outros três pescadores, embarcou em uma jangada rumo ao Rio de Janeiro exclusivamente para protestar junto ao presidente Getúlio Vargas contra o abandono dos pescadores. Jacaré morreu de forma trágica no mar, em uma tempestade, durante a filmagem da viagem feita pelo diretor norte-americano Orson Welles. Dessa forma, podemos perceber que a Prainha é um berço de luta dos pescadores cearenses.

Em 1980 a luta reivindicatória por melhores condições de trabalho e apoio à pesca artesanal torna-se um movimento estruturalmente articulado. Muitas entidades passam a apoiar a causa, como o Conselho Pastoral dos Pescadores, por meio das Comunidades Eclesiais de Base da Igreja Católica, criado a partir da articulação da comunidade da Prainha com os movimentos estaduais e nacionais de pesca (GALDINO, 2014).

O fim da década de 1980 e o início da década de 1990 são marcados por vários conflitos no mar com a invasão de vários barcos piratas apreendendo lagostas de forma ilegal com compressor, prática proibida pela legislação por comprometer a 


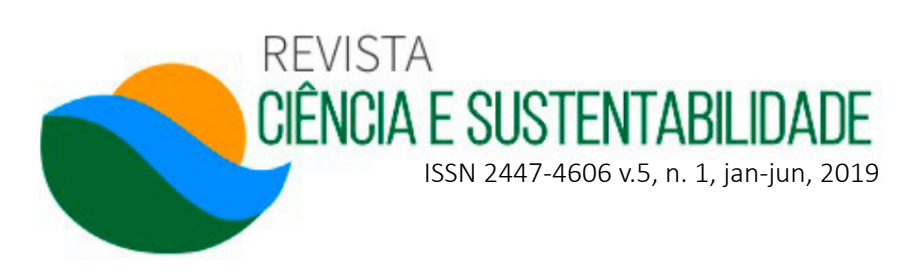

reprodução de mariscos. Os pescadores da comunidade passaram a se organizar com boa parte das comunidades do litoral leste do Ceará para combater essa prática, mas o conflito culmina com o assassinato de pescadores da região (GALDINO, 2014).

Em 1989, é criada a AMPCV, com o apoio do Centro de Defesa dos Direitos Humanos (CDPDH) da Arquidiocese de Fortaleza, com forte influência do religioso e militante de direitos humanos internacionalmente reconhecido Dom Aloísio Lorscheider (PRAINHA, 2011).

Um processo de luta por terras da comunidade envolve uma disputa judicial que se inicia no fim da década de 1970. Entre 1976 e 1978, um grileiro comprou um pequeno terreno a cerca de dois quilômetros da praia e conseguiu registrar no cartório uma área de 749 hectares adquiridos por "usucapião", incluindo boa parte de faixa da praia, embora já houvesse moradores locais ocupando aquele espaço. Em 1984, mesmo o objeto desse processo de usucapião sendo de competência federal, a juíza da Comarca de Beberibe julgou a ação favorável ao grileiro. Iniciaram-se embates judiciais que também incluíram situações de violência física entre a comunidade e uma imobiliária, que teria comprado a terra do grileiro. Em 1989, a recém-criada AMPCV, juntamente com os advogados da CDPDH, iniciam ação rescisória, buscando a demarcação e a devolução da terra para a comunidade. Em 2001, a Justiça julga procedente a ação rescisória, anulando o registro de usucapião. Em 2009, a partir dos esforços da comunidade, é decretada a Reserva Extrativista (Resex) em uma área de 29.794 hectares, uma das maiores conquistas da comunidade. Com isso, esta área da praia passa a ser gerida coletivamente. (GALDINO, 2014)

Existem diversos tipos de Unidade de Conservação Ambiental. A Reserva Extrativista (Resex) é definida como uma área de domínio público reservada ao extrativismo, tendo como beneficiários comunidades nativas cuja subsistência baseiase no extrativismo e, complementarmente, na agricultura familiar e na criação de animais de pequeno porte. A Resex tem como propósito a proteção dos meios de vida e a preservação da cultura dessas populações, além de assegurar o uso sustentável dos recursos naturais. (BRASIL, 2000).

A Resex é gerida por um Conselho Deliberativo, constituído por representantes de órgãos públicos, de organizações da sociedade civil e de populações tradicionais residentes na área. Nela, a visitação pública é permitida, desde que compatível com os interesses locais e de acordo com o Plano de Manejo da Área (BRASIL, 2000). Na 
prática, ela promove a preservação do meio ambiente, resguardando a localidade de interesses exclusivamente comerciais, como a pesca predatória, prática que torna inviável qualquer projeto de sustentabilidade.

A Resex protege também a atual forma de interação cultural da praia, pois proíbe a venda da terra, assegurando aos moradores o direito de nela morar e de subsistir, evitando o turismo predatório e a especulação imobiliária, além de preservar o meio ambiente e fortalecer os laços comunitários.

A PCV foi escolhida como lócus desta pesquisa por conta da forte participação social dos seus membros, que foi construída durante o percurso histórico do local e que se mostra imprescindível para a criação de um projeto de sustentabilidade e proteção ambiental como a criação da Resex. Além disso, o processo de documentação da história comunitária, bem como de sua reprodução intergeracional e das mobilizações coletivas em torno de questões fundamentais para o cotidiano e sobrevivência da comunidade contribuiu para a articulação de movimentos políticos que se ampliaram e impactaram outras comunidades. Isso se ilustra no Fórum dos Pescadores do Ceará, que foi criado na PVC e ajuda a fomentar políticas públicas de proteção em nível estadual e nacional.

\section{A LUTA COMUNITÁRIA}

O primeiro grupo-focal chamou a atenção do pesquisador no modo com a palavra circulava de forma tranquila e contínua. Apesar do grupo ter sido composto por quinze pessoas, em nenhum momento dois sujeitos falaram ao mesmo tempo. Sempre que algum membro queria falar, levantava a mão e só tomava a palavra quando o anterior terminava a sua fala. Essa naturalidade de diálogo é reflexo de uma intensa agenda de reuniões comunitárias, nas palavras de um morador: "Mas pra resistir a isso, desde o início, se tem uma dinâmica de reunião. Eu acho que não tem um dia na semana, de domingo a domingo que na comunidade não aconteça uma reunião." (Participante 08 )

A militância gerada pela participação comunitária não se restringe às fronteiras da localidade, articulando-se a outros movimentos de âmbito estadual, nacional e até global. Scherer-Warren (2002) usa o termo "glocalização" para relatar a possibilidade de criar alternativas à globalização a partir de iniciativas de resistência da sociedade 
civil local e de suas redes transnacionais, fazendo com que o global se internalize no associativismo local.

O impacto do global no local e do local no global fica evidenciado quando estamos falando de meio ambiente. O problema do "desaparecimento" da lagosta na PCV é um exemplo disto, pois muitas evidências apontam que um dos seus causadores é a mudança de temperatura dos oceanos, o que, por sua vez, encontra relação direta com o efeito estufa e com a destruição da camada de ozônio provocada pelo modo de vida das civilizações modernas. Assim, se as populações locais sofrem por um problema gerado em escala global, nada mais adequado do que se unam e pressionem por soluções efetivas para os problemas globais que estão lhes atingindo.

É notório que toda a comunidade conhece e valoriza sua história de luta, reproduzida oralmente de forma intergeracional. A comunidade é cônscia do esforço e da união comunitária: "A gente tem que ser forte, mas não só de boca, mas de agir também. Então nós temos essa praia bela, que você hoje está aqui porque aqui é uma história muito longa, e com um esforço muito grande das pessoas né? Dos nativos aqui da região" (Participante 15).

Os moradores falaram também sobre como o ritmo da comunidade contribui para essa aproximação entre os moradores, o que colabora para a organização comunitária. A integração e a busca por soluções na comunidade não se estendem apenas às reuniões oficiais, mas também no cotidiano local. Esse fenômeno ocorre, em parte, devido à forma como a pesca impacta no cotidiano, posto que essa é a principal atividade de subsistência. A pesca é uma atividade que está diretamente vinculada à maré, não podendo ser realizada exclusivamente de acordo com a vontade ou necessidade de quem da pesca vive, o que impossibilita uma carga horária diária ou a demarcação de um "horário de trabalho". O mar indica o momento da ida a trabalho e o momento da volta para casa, de forma que a relação desta pequena comunidade pesqueira com o tempo é diferente da relação, por exemplo, de moradores das zonas urbanas. A maré não funciona de acordo com o horário comercial. Os habitantes, assim, parecem ter mais oportunidades de discutir sobre seus problemas e de potencializar ações coletivas. Aqueles sujeitos que trabalham em outras atividades, com horários menos flexíveis, relataram sentir falta de ter uma proximidade maior com os assuntos da comunidade.

Participar das ações comunitárias e opinar sobre questões coletivas é de extrema 
importância para os residentes da PCV. As reuniões são vistas como fundamentais para as conquistas sociais da comunidade: "Se tem uma reunião ou duas e se é pra debater pautas de interesse da comunidade, seja pro território, seja pra pesca, seja pra saúde, seja pra qualquer seguimento da comunidade, a gente tá. Isso está entrelaçado nas veias das lideranças de muito moradores" (Participante 04).

Para Freire (1970), a formação da consciência crítica, ou seja, o processo de conscientização dos sujeitos, só ocorre por meio do diálogo. É por ele que a comunidade pode se emancipar e se desenvolver.

Uma das questões relevantes neste estudo foi compreender de que forma ocorrem os processos de participação comunitária dos moradores da PCV, que se destacam pelo fortalecimento de vínculos, preservação da cultura local e da predominância das questões coletivas sobre as individuais. No grupo focal, encontramos algumas respostas a estes questionamentos. As falas apontam para um engajamento nos movimentos políticos, bem como para a valorização destes. Seus integrantes demonstram prazer, vício, paixão em compartilhar os espaços formais de fala, ainda que admitam o cansaço:

\footnotetext{
uma das coisas que eu vejo é que o movimento se torna uma paixão da gente, e uma coisa que a gente não consegue fugir. A gente pode até dizer assim, não, eu não quero mais, eu não vou participar mais, mas, é uma coisa que é como a droga, cada vez você quer mais participar, mas você quer tá dentro. (Participante 02)
}

Sawaia (2002) discorre sobre a importância de que participação deixe de ser um imperativo categórico, que obriga o sujeito a renunciar à suas necessidades e desejos particulares como condição para viver em sociedade. Para a autora, a participação não é um dever, uma obrigação ou um ato de moralidade; e também não é realizada por altruísmo, mas pelo desejo de ser feliz e de ser livre; de não ser comandado e governado.

Boa parte dos moradores mais engajados da comunidade são nativos da região e trazem uma história de ligação afetiva com o movimento, calcada em sua própria formação familiar e comunitária. O sentido de luta comunitária desses sujeitos parece estar entranhado numa cultura formadora da de suas próprias identidades. $\mathrm{Na}$ AMPCV encontramos registros fotográficos de membros e líderes ainda crianças, brincando entre si, enquanto os pais já ocupavam os espaços de reunião e davam início 


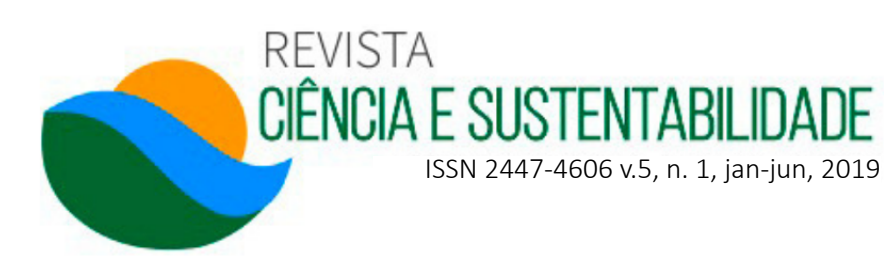

a processos para a construção do movimento. Dessa forma, boa parte das lideranças comunitária da PCV cresceram dentro do movimento, ouvindo as discussões de seus pais, tios e vizinhos sobre como construir um lugar melhor para todos:

\begin{abstract}
E aí a gente que era mais jovem, os filhos, ficava brincando enquanto os adultos traziam a gente, aí acabamos com o passar do tempo se envolvendo nisso, aí depois veio o grupo de jovens, aí vêm os conselhos, como a gente estava dentro do movimento acaba se envolvendo, tomando gosto pelas coisa. (Participante 09)
\end{abstract}

Evidenciamos que a identificação da história de grande parte da militância se construiu pautada na história familiar e comunitária dos sujeitos. Esse tipo de discurso alimentou vários relatos, muitos deles emocionantes, e o sentimento que transmitiam quando falavam de seu passado, de sua história, de sua infância e de suas identidades escapam da possibilidade de serem aqui transmitidos. Essas raízes históricas se mostraram um fator relevante na explicação do forte engajamento desta comunidade.

Algo que ficou perceptível nas discussões dos grupos focais foi como as posições ocupadas pelos sujeitos dentro do movimento são rodiziadas. Não parece haver nenhum centralismo: muitos participantes relataram fazer parte de diferentes posições dentro do movimento. Assim como aparentemente muitos passam algum tempo em posições de maior destaque e das quais é necessária uma maior dedicação de tempo, sendo posteriormente substituído por outros.

\footnotetext{
Já estou com quarenta, quarenta e um, quarenta e dois anos aqui [no movimento comunitário] construí minha família aqui, tenho mais de 40 anos aqui, participei de todos os movimentos da PCV depois que foi criado o movimento comunitário. Todo o movimento que teve aqui eu participei. Fui presidente da associação, fui presidente de conselho, participei de todos os conselhos criados nessa comunidade, de saúde de educação, sei nem de quantos conselhos foi criados, participei de vários. (Participante 01)
}

Parte dos moradores de idade mais avançada, antes participantes assíduos das mobilizações, demonstra exaustão no que diz respeito à participação do movimento, embora fique explícito que o desejo de participar ainda persista: "Participo porque tenho gosto [...] estou velho não tenho mais idade pra essas coisas não, mas participei muito" (Participante 16). 
As novas gerações vão paulatinamente assumindo os espaços antes ocupados pelas antigas lideranças, ocasionando uma transição lenta e contínua, sem rompimentos imediatos, unindo o vigor e a vontade das novas gerações com a experiência das mais velhas: "E hoje a gente tem muito que substituir os mais velhos, né? Muitas lideranças foram os nossos pais, alguns dos que começaram já não estão aqui entre nós, já faleceram, outros não moram mais na comunidade, mas a luta está aí, a luta continua" (Participante 08).

Apesar do processo de renovação do movimento vir ocorrendo gradualmente de forma bastante positiva, em algumas falas os sujeitos demonstraram medo de que a história de luta venha a se perder ou de que as novas gerações não tenham o sentimento de pertencimento pelo lugar onde moram. Uma das moradoras e antiga militante das causas comunitárias ressaltou:

\begin{abstract}
Agora isso precisava muito passar numa assembleia grande, passar nas escolas, e os pais nas suas casas passar para os seus filhos, a comparação daqui pra outra comunidade. Porque o que eu vejo hoje uma coisa que precisa ser trabalhada muito é: Como as crianças e como os jovens valorizar mais a nossa comunidade? O lugar que você mora, a casa que você mora, você mesmo. Meus filhos, meus netos, meus bisnetos. Por que passar a coisa de pai pra filho isso é muito importante. (Participante 10)
\end{abstract}

É notável que os participantes demonstram preocupação com a sustentabilidade local, o que entra em consonância com a definição de desenvolvimento sustentável da Comissão Mundial sobre Meio Ambiente e Desenvolvimento (1988), que diz que o desenvolvimento sustentável é aquele que garante «atender as necessidades do presente sem comprometer a capacidade de as gerações futuras atenderem também às suas» (p. 9). Isso se manifesta na vontade de que seus filhos tenham terra e possam viver melhor do que eles viveram, em um ambiente agradável e preservado.

A identidade dos sujeitos como participantes dos movimentos comunitários, de forma direta ou indireta, desde a mais tenra idade, parece ter contribuído para que o processo de engajamento seja tão consistente neste local. Assim, preservar a história do movimento se mostra de grande importância para a preservação da identidade desta comunidade. 


\section{O MODO DE VIDA NA COMUNIDADE}

Mesmo a PVC contando com pouco mais de 1100 moradores, algo muito recorrente em seus discursos sobre modo de vida foi o fato de que todos na localidade se conhecem. O cotidiano que envolve espaços de trabalho, políticos e de lazer compartilhados contribui na identificação de um coletivo enquanto comunidade. Soma-se a isso o tratamento pessoal que os sujeitos dispensam uns aos outros: "Na comunidade 99\% tem apelido, você encontra as pessoas por apelido" (Participante 08). Essa fala aponta para um sentido de unidade comunitária, uma intimidade compartilhada e um reconhecimento recíproco de seus membros.

$\mathrm{Na}$ Prainha, à tarde, é comum encontrarmos grupos de pescadores e moradores na praia, embaixo dos barracões, em longas conversas. No trabalho de campo, percebemos que muitos nem mesmo foram ao mar, mas foram devagar se juntando àqueles que estavam voltando de sua atividade de trabalho, chegando a formar grupos de vinte a trinta sujeitos, em sua maioria homens, conversando sobre assuntos diversos. A falta de horários rígidos de trabalho parece contribuir com um clima de tranquilidade e incentivar a interação entre os moradores.

O tempo disponível e a liberdade de realizar as rotinas de trabalho de forma mais flexível parece ser muito relevante para o trabalho comunitário. O trabalho faz parte da vida do pescador de uma maneira muito orgânica: negociações de horários acontecem com a natureza, de modo que ele organiza seu tempo com possibilidades de ficar disponível a demandas da comunidade. "Aqui é bom porque a gente tem muito tempo e liberdade para se dedicar as coisas coletivas" (Participante 02).

Tuan (1980) retrata que ambientes abertos e naturais aumentam a sensação de apego e de agradabilidade dos indivíduos. Além do contato com a natureza e da tranquilidade no ritmo do dia-a-dia, outro fator importante é a sensação de segurança que os moradores experimentam na sua localidade:

\footnotetext{
Outra coisa que me deixa feliz de ver isso aqui, que nas outras comunidades eu não encontro, é essa liberdade que a gente tem de você sair dez horas da noite de casa vai pra casa de qualquer outra pessoa numa precisão. $E$ a gente tem isso assim garantido, a gente vai sabendo que vai chegar em casa tranquilo, que não vai acontecer nada, que em outros lugares a gente não pode fazer isso. (Participante 07)
}

Também houve relatos que colocam a comunidade como um lugar no qual a 
solidariedade e a partilha acontecem de forma bastante recorrente. Ao contar sobre algumas situações rotineiras, os moradores vão narrando como realizam uma rede de cooperação mútua:

Quando a pessoa chega do mar sempre tem aquele amigo mais próximo, aquele parente, para o qual você tira um peixe, dá um peixe. Isso continua muito forte, aquele parente você sempre dá um peixe, partilha. Você vê que o cara chega do mar muitas vezes o cara fica quase sem levar nada porque tirou o de comer, chegou um, partiu, outro, partiu, ai chegou o derradeiro amigo, partiu o peixe. (Participante 08)

E outra coisa que é importante, eu achava muito legal, até um tempo desse atrás quando alguém da comunidade caía doente, tinha uma pessoa, qualquer uma pessoa: "Um amigo nosso caiu doente!". Aí a gente ia pra debaixo do barracão, aí uma pessoa se encarregava: "Cada jangada que chegar vamos pedir um peixe pra fulano" (Participante 07)

Assim, os vínculos comunitários na região se formam também através de relações de solidariedade e ajuda mútua. No início da formação da comunidade, o isolamento fazia com que as relações econômicas fossem muito mais informais do que nas cidades grande. A permuta era muito praticada em substituição da relação monetária formal, mais rígida. Hoje a PCV já é bem mais monetarizada, entretanto, a tradição de uma economia informal e solidária é um legado passível ainda de ser notado: "Chegava do mar o pescador dava peixe pra aquelas pessoas que estavam lá depois do morro aculá, que a gente chama campestre, vinha com a farinha, com o coco, com a goma, dava pra o pescador, o pescador dava o peixe" (Participante 01). A preservação de parte desses aspectos pode ter sido um grande diferencial para que a localidade se tornasse referência na luta comunitária, pois são indicadores de um pensar e agir coletivos. Outro fator relevante observado na PCV foi a identificação da comunidade como originária de apenas duas famílias. Isso faz os moradores se sentirem como se fossem todos parentes, se reconhecendo como unidade:

Em um local onde partilhar o alimento é prática comum, compartilhar expectativas e lutas coletivas fica bem mais fácil: "Então essa solidariedade de repartir o peixe já vem de raiz, como os meninos disseram, até que chega a esse ponto do movimento quando a gente chegou ao ponto de ter que se organizar em comunidade pra lutar por um objetivo comum" (Participante 01). Vale ressaltar que, apesar do clima de solidariedade que retratamos, as opiniões na Prainha não são todas convergentes. É intensa a disputa entre aqueles a favor que a extensão da Resex inclua a parte 


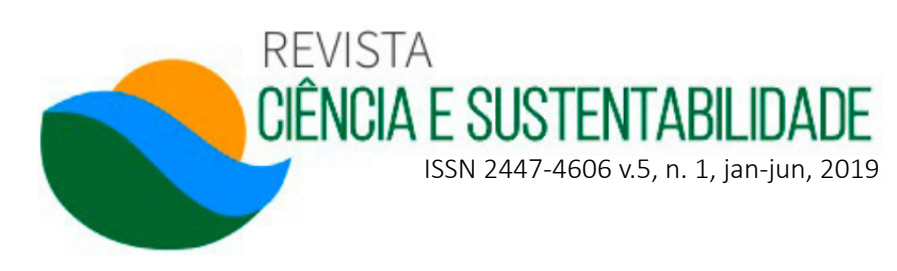

marítima e terrestre e aqueles que defendem que se restrinja à parte marítima. Estes últimos são compostos principalmente por pessoas que não são engajadas na AMPCV.

Apesar de um discurso majoritário que retrata a comunidade como bastante solidária, alguns moradores também relataram mudanças que vem ocorrendo concomitante a um processo de enfraquecimento da liga comunitária. No entanto, ressaltam que tais ocorrências vêm acontecendo em ritmo mais lento, em comparação com comunidades próximas:

\begin{abstract}
Essa coisa da solidariedade é muito forte, mas nós estamos perdendo, essa relação entre os vizinhos está caindo muito, no passado apesar dos vizinhos serem mais distantes, cinquenta ou sessenta metros uns dos outros, eles conversavam mais. Por outro lado, eu compreendo que a internet, a televisão, esse tempo que nós utilizamos na televisão, que nos dá essas informações, ou não, era o tempo que nós utilizávamos para conversar muitas vezes com o vizinho. (Participante 02)
\end{abstract}

Vale ressaltar que, ao serem questionados sobre as relações atuais de solidariedade, alguns dos participantes dos grupos conjugavam os verbos no passado, como se estivessem falando de um outro tempo, mas, logo depois, muitas vezes um outro morador, ou mesmo o próprio sujeito, retificava: "Mas ainda acontece isso, mas menos que antes". O avanço da globalização gera tensões para a formação de um estilo de vida comum a todo o planeta, e este estilo segue padrões e preceitos do sistema capitalista, onde há supervalorização do consumismo e do individualismo.

\begin{abstract}
A globalização e seus coronários comércio e comunicação globais criam pressões em direção a uma uniformidade cultural de estilos de vida. $O$ alinhamento progressivo da globalização trouxe uma padronização de valores e de um crescente anonimato. Nesse contexto ela é considerada, por muitos de nossos cidadãos, como ameaça a identidade. (MOSER, p. 190, 2001)
\end{abstract}

Ainda por volta de 1980, a PCV era totalmente isolada geográfica e socialmente. Os trajetos eram feitos apenas a pé ou por animais e raramente os sujeitos saíam da localidade. Um veículo (Jeep) vinha apenas semanalmente à localidade e era considerado o transporte coletivo, pois era responsável pelo transporte de cargas e mercadorias até pessoas doentes, e também de alunos que precisavam estudar fora da comunidade. (GALDINO, 2014).

Atualmente, a estrada liga a PCV à Fortaleza em menos de duas horas e o 
acesso a centros urbanos próximos pode ser feito em minutos pelos moradores. Muitos jovens cursam ensino básico ou superior em cidades vizinhas e deslocamse diariamente, vivenciando novos contextos culturais. Os moradores têm acesso à Internet, que lhes conectam globalmente e permite que pescadores utilizem o sistema GPS de seus celulares para auxiliar no trabalho de pesca.

Apesar dos relatos que citam um possível decréscimo nos sentimentos de solidariedade do local, os sujeitos seguem se percebendo como uma comunidade especial, que possui uma história ímpar, servindo de exemplo para seu entorno e para todo o litoral leste do Ceará. A PCV já ganhou cinco prêmios internacionais de turismo socialmente responsável e boa parte da política nacional de pesca saiu de discussões nesse território. Sua organização comunitária serve de modelo para boa parte da costa litorânea brasileira.

Nos grupos focais os moradores compararam sua comunidade com lugares como a cidade de Fortaleza, ressaltando que nestes espaços metropolitanos a população vivencia um estilo de vida mais estressante, com carência de segurança e baixo contato com a natureza. Já em comparação com as praias vizinhas, a tendência dos sujeitos foi de perceber sua comunidade como um local especial, devido suas conquistas sociais. Os participantes relatam que localidades do entorno não conseguiram os mesmos direitos, especialmente no que concerne à terra. $\mathrm{Na}$ PCV, as novas gerações têm a garantia do direito ao terreno para construir a sua moradia, enquanto em outras comunidades, a especulação imobiliária e o avanço do turismo predatório retiram do morador o direito à terra. A luta da comunidade gerou a manutenção de direitos e de condições dignas e sustentáveis de sobrevivência, o que não existe de forma tão evidente localidades próximas.

Os moradores fizeram uma crítica à visão dos "prainheiros"”, em especial os mais jovens, os quais, em uma busca de adequação aos modos de vida que a sociedade capitalista impõe, diminuem a relevância do percurso histórico, do modo de vida e das conquistas sociais da comunidade. Eles atribuíram isso ao fato de que alguns dos jovens moradores não têm vivências fora de sua realidade imediata, não conseguindo ter uma percepção mais ampla das condições de vida de comunidades próximas, que em geral são mais carentes de recursos.

Por trás desta crítica, duas visões distintas sobre a PCV parecem se desenvolver. É interessante que os sujeitos que criticaram a forma de pensar dos "prainheiros" ${ }^{1}$ Nativos da Prainha do Canto Verde. 
sejam também prainheiros, apesar de se identificarem como alguém que pensa diferente. De uma forma geral, essa crítica parece estar direcionada, em especial, a parte das pessoas que não participam das atividades comunitárias e que têm uma maior tendência a perceber a localidade sob aspectos mais negativos.

Por outro lado, em outros momentos, o "prainheiro" era retratado como sujeito com um bom nível de informação e debate da realidade, não só local, como também nacional e internacional, bem superior aos sujeitos de seu entorno: "O prainheiro ele é muito informado. Se nós for pegar um prainheiro, tanto faz ser jovem como não, comparado com alguém da cidade ele está muito mais atualizado nas notícias [...] os prainheiros já estão lá na frente" (Participante 02).

Os moradores reconhecem a importância da Resex, relatando que se sua criação não fosse possível, o poder da mobilização popular provavelmente seria menor. Isso porque os incentivos governamentais gerados a partir dela, como empréstimos para desenvolvimento econômico, bolsas, etc, ajudam a articular a comunidade, provendo recursos necessários para a realização da mobilização e mostrando que a articulação e luta dão retorno, reforçando o compromisso e o empenho comunitário.

Além das vantagens expostas, a Resex deu muita visibilidade para a comunidade da PCV. O fato de se instituir uma Reserva, além das facilidades de incentivo promovidas pelas políticas públicas, também traz maior destaque e reconhecimento da comunidade por pessoas que estão distantes, até mesmo em outros locais do País, que podem unificar as bandeiras de luta e ampliar ainda mais as conquistas.

AReserva é percebida como um marco dentro da história de luta da comunidade, como uma grande conquista que vem possibilitando outras conquistas: "Parecia que a luta mesmo, essa coisa mais ferrenha, ia parar com a criação da reserva, mas não, continua aí, parece que na mesma força né? Se ainda tem embate a gente continua combatendo" (Participante 11). A reserva hoje potencializa essa luta, pois legitima as decisões coletivas dos moradores, ao passo que contribui com a conservação da natureza, essencial para a sobrevivência de seus habitantes. A Reserva é percebida como fundamental não só na preservação física do ambiente, incluindo aí sua biodiversidade, como também na preservação cultural e do atual modo de vida. 


\section{CONSIDERAÇÕES FINAIS}

Esta pesquisa constatou que na PCV a participação social ocorre de forma sistemática e de forma intergeracional. A criação da Resex é uma conquista de seus habitantes que auxilia na preservação do meio ambiente e no desenvolvimento sustentável desta comunidade, sendo ainda essencial no combate efetivo da pesca predatória e na garantia do direito à terra para a população local. Vale lembrar que a Resex também facilita pequenos investimentos, através do recebimento de empréstimos e subsídios para o desenvolvimento econômico local.

Embora a participação evidentemente não atinja todos os moradores, é explícito que se configura como uma localidade que se destaca neste quesito. A participação no local não está ligada apenas a componentes racionais de união comunitária instrumental. Ela é apontada pelos participantes especialmente a partir dos vieses afetivos: dos desejos, das paixões e dos vícios. A participação se mostrou relacionada ao sentimento de pertencimento comunitário e promotora do orgulho de fazer parte de um coletivo, fazendo com que para além das existentes disputas internas coexistam sentimentos de solidariedade e de partilha.

Talvez a questão afetiva explique parcialmente a resistência de um dos maiores desafios das lutas comunitárias: a continuidade. Além disso, o rodízio de funções apresentado pelos moradores torna esta tarefa menos penosa, tendo em vista que parte das organizações comunitárias naufragam justamente porque as tarefas ficam centralizadas em poucas pessoas.

A habitualidade da participação ocorre há algumas décadas, de forma que sua valorização já se constitui um componente cultural transmitido transgeracionalmente. Isso comunga com o fato que todos descenderam de apenas duas famílias e muitas vezes explicitaram um sentimento de parentalidade. A participação comunitária parece ser motivada por um forte senso de continuidade geracional, fundando-se em um passado no qual os pais ensinaram a preservar e olhar o futuro no qual a preocupação e o cuidado com os filhos se faz presente. Em vários momentos, os moradores explicitaram a importância da participação comunitária e da preservação ambiental como algo de grande importância a ser deixado para as gerações posteriores. A participação se volta em primeira instância para a busca pela preservação da natureza, representada especialmente pela terra, fonte de proteção, e em segunda instância 
pelo mar, fonte de sustento. No entanto, essa dimensão é transcendida e se constitui também como uma busca de preservação do seu modo de vida, ou seja, de sua identidade.

Como vimos, a globalização cria tensões em direção a uma uniformidade cultural de estilos de vida, que chegam a ser uma ameaça à identidade de determinado locus. A participação social da PCV parece fazer uma força contrária a esse sentido, em busca de manter um modo de vida menos individualista e mais solidário sem o ideal, talvez impossível, de conservar a vida comunitária como era antigamente. O movimento organizado de moradoras da PCV se utiliza de recursos e tecnologias oriundos do processo de globalização como forma de resistência contra esta tendência homogeneizante da cultura. Essas mulheres se conectam com outras causas semelhantes ou complementares à sua. Como vimos, a comunidade da PCV foi fundamental na construção de várias políticas públicas de proteção pesqueira nacional, tornando uma significativa referência tanto para outras comunidades, como para pesquisadores e agentes diversos que atuam nesses espaços.

Scherer-Warren (2002) explana sobre a importância de se fazer redes de solidariedade e pensar estratégias entre os atores e as organizações de luta cidadã. O autor fala da importância de que redes construídas a partir do tecido social comunitário cruzem-se com redes construídas a partir do tecido social associativista, para que questões que surjam dentro de um locus comunitário e se projetem em escala nacional ou mesmo planetária, de forma que novas formas de solidariedade sejam estabelecidas entre os povos.

A contraposição entre a globalização, que pressiona os moradores à uniformidade cultural, gerando valores mais individualistas, e a resistência comunitária, que percebe como relevante a valorização de um modo de vida mais coletivo, gera diversas contradições e disputas internas e externas. Assim, é fundamental que, diante de um cenário de mudanças políticas, econômicas e sociais, a Prainha do Canto Verde possa preservar sua história, para que sirva de exemplo e inspiração a muitas outras comunidades, praianas ou não.

\section{REFERÊNCIAS}

BRASIL. Constituição Federal: Lei 9.985, de julho de 2000. Regulamenta o art. 
225, § 10 , incisos I, II, III e VII da Constituição Federal, institui o Sistema Nacional de Unidades de Conservação da Natureza e dá outras providências. Brasília, 18 de julho de 2000. Disponível em: http://www.planalto.gov.br/ccivil_03/leis//9985.htm. Acesso em: 28 set. 2016.

BODERNAVE, J.E.D. O que é participação. São Paulo: Brasiliense, 1983.

DEMO, P. Participação é conquista: noções de política social participativa. 6 ed. São Paulo: Cortez, 2009.

FREIRE, P. Pedagogia do oprimido. Rio de Janeiro: Paz e Terra, 1970.

Conscientização: teoria e prática da libertação: uma introdução ao pensamento de Paulo Freire. São Paulo: Cortez e Moraes, 1979.

GALDINO, J. W. Educação e movimentos sociais na pesca artesanal. Fortaleza: UFC, 2014.

MOSER, G. Psicologia Ambiental no Novo Milênio: Integrando a Dinâmica Cultural e a Dimensão Temporal. In: TASSARA, EDA (Org.). Panoramas interdisciplinares para uma Psicologia Ambiental do Urbano. São Paulo: EDUC, 2001.

PRAINHA do canto verde. Beberibe, 2011. Disponível em: http://

prainhadocantoverde.org/associacao-dos-moradores/. Acesso em: 2 mar. 2019.

SAWAIA, B.B. Participação social e subjetividade. In: SORRENDINO, M.

Ambientalismo e participação na contemporaneidade. São Paulo: EDUC, 2002.

SCHERER-WARREN, I. Movimentos sociais e participação. In: SORRENDINO, M. Ambientalismo e participação na contemporaneidade. São Paulo: EDUC, 2002.

TUAN, Y.F. Topofilia: um estudo da percepção, atitudes e valores do meio ambiente. São Paulo: Difel, 1980.

VYGOTSKY, L. S. Os métodos de investigação reflexológicos e psicológicos: Teoria e método em psicologia. São Paulo: Martins Fontes, 1996. 